\title{
COMMENTARY
}

\section{Use of Lesion Response Rate in Actinic Keratosis Trials}

Rolf-Markus Szeimies · Petar Atanasov $\cdot$ Robert Bissonnette

Received: August 3, 2016 / Published online: September 19, 2016

(C) The Author(s) 2016. This article is published with open access at Springerlink.com

\section{ABSTRACT}

Complete patient clearance is often required by regulatory agencies for the approval of treatments for actinic keratosis (AK). However, an increasing number of clinicians have challenged the use of this measure in clinical practice and its interpretation. It has been argued that complete patient clearance often underestimates the clinical benefit of a drug and is influenced by a number of key confounding factors, such as number and distribution of lesions, at baseline. Lesions response rate is one alternative which has been suggested as more relevant due to its applicability to clinical practice and closer reflection of the clinical value of the drug. This paper provides an

Enhanced content To view enhanced content for this article, go to http://www.medengine.com/Redeem/ 10E6F060024FEB6C.

Rolf-MarkusSzeimies $(\square)$

Department of Dermatology and Allergology,

Vest Clinic, Recklinghausen, Germany

e-mail: Rolf-Markus.Szeimies@Klinikum-Vest.de

P. Atanasov

Amaris, London, UK

R. Bissonnette

Innovaderm Research Inc., Montreal, QC, Canada updated perspective on the topic and details the current thinking on the role of complete clearance and lesion response rate in the context of AK.

Funding: Galderma.

Keywords: Actinic keratosis; Clinical practice; Clinical trial; Efficacy; Lesion clearance; Lesion response rate; Solar keratosis

Actinic keratosis (AK) is a common epithelial non-infiltrative lesion caused by prolonged exposure to ultraviolet radiation, which damages cell-cycle regulators, and leads to the proliferation of epidermal keratinocytes. It is recognized as one of the earliest clinical events on a continuum which may lead to the development of invasive squamous cell carcinoma (SCC) [1]. Patients often present with multiple AK lesions, characteristically distributed on sun-exposed areas, such as the face, bald scalp, chest, back of the hands, and forearms. In Europe, between $11 \%$ and $25 \%$ of people, over the age of 60 are estimated to have at least one $\mathrm{AK}$ lesion [2]. $\mathrm{AK}$ is considered chronic and typically characterized by lesion 
clearance as a result of therapy, followed by the recurrence of lesions continuously over time [1].

The primary goal of AK therapy is the clearance of lesions to reduce the risk of further progression into SCC [3]. In addition, there is a growing consensus and recognition among clinicians, regarding the significance of actinic field damage, its relevance to the pathology of SCC, and the importance of attentive management [4]. Treatments strategies can be broadly divided into lesionand field-directed. In patients with extensive photodamage, multiple lesions and field cancerization treatment of the field are considered most appropriate, given the importance of treating both clinically visible and subclinical lesions [3].

The choice of efficacy endpoints in AK clinical trials assessing field-directed therapies as well as their interpretation has been discussed previously by Wolf et al. [5]. Traditionally, the count of the total number of clinically significant lesions in a selected area prior to and after a course of treatment has been commonly used [5]. Subclinical lesions which become visible during the course of therapy are also included as part of the efficacy assessment, however, making discrimination between inflammatory response of subclinical lesions and sun-damaged skin difficult.

Complete patient clearance rate is defined as the proportion of patients with no clinically visible AK lesions (i.e. 100\% clearance) in a pre-defined treatment area at specific times of assessment. It is one of the most commonly used efficacy endpoints in AK clinical trials, and, as such, is commonly required for regulatory purposes. Some investigators, however, have challenged the clinical relevance of this endpoint and its clinical meaningfulness to the "real-world" setting
[6-8]. As AKs are often numerous and difficult to see, clinical trials are often designed to treat a limited area $(5 \times 5 \mathrm{~cm}$ for example). This strategy makes mapping and evaluation of AKs easier. Complete clearance of lesions within such a small field is a realistic goal; however, complete clearance rates from studies where only a small field has been treated cannot be extrapolated to clearance of lesions on the entire face. In fact, complete clearance of numerous lesions on the entire face is rarely achieved in clinical practice for patients with multiple lesions [9]. Subclinical lesions can also become visible during treatment periods, making the evaluation of complete clearance very difficult. This measure is further undermined by the chronic nature of $\mathrm{AK}$ which leads to lesions' inevitable recurrence and subsequent re-treatment. Complete patient clearance results are not necessarily reflective of the overall long-term outcomes associated with $\mathrm{AK}$ lesions and tend to underestimate treatment benefits [6, 8]. For example, a lesion clearance rate of $90 \%$ (e.g., a reduction from 40 to 4 lesions) can be considered as a failure based on the complete patient clearance criteria, regardless of its obvious clinical relevance and patient benefit. Furthermore, complete patient clearance is known to be confounded by a number of factors, including the development of subclinical lesions during treatment, the number of lesions at baseline within the treatment area assessed, as well as the size of the assessed treatment area $[5,10]$. Treatment success may also depend on the location of lesions, with those on face and scalp usually responding more than those on the body extremities [3].

Notably, in some AK trials [11], the assessment area on which efficacy results are based can be considered fairly restrictive $\left(\sim 25 \mathrm{~cm}^{2}\right)$, and while this is sufficient for 
registration purposes, in clinical practice, the applicability of such restriction can be limited. Other studies include more extensive areas of the face and scalp $\left(>200 \mathrm{~cm}^{2}\right)$ [12]. The obvious consequences of this would be that the complete patient clearance in trials which involve larger treatment areas can be expected to be smaller than those assessing smaller areas and, therefore, underestimate the clinical value of the treatment [8]. Similarly the number of lesions at baseline is known to affect the complete patient clearance [7]. It is reasonable to expect that in patients with a higher number of lesions at baseline, the complete clearance could be lower compared with those with a lower baseline lesion count. Beyond the impact of these confounding factors, complete patient clearance can be an inappropriate outcome in certain cases, particularly where extensive actinic field damage is present and field-directed therapy is required to manage subclinical lesions. Complete patient clearance does not capture the full benefit of field-directed therapies and fails to adequately reflect the current understanding of the pathophysiology of AK which highlights the importance of management of both clinical and subclinical lesions.

Given the limitations of complete clearance as a meaningful outcome, alternative measures of efficacy have been suggested as more clinically relevant in practice $[5,7,8]$, including lesion response rate and patient partial clearance with variable thresholds. The International League of Dermatological Societies (ILDS) has identified the rate of lesion clearance as one of several critically important efficacy outcomes for the assessment of efficacy of treatments for AK [1], as it is highly sensitive and widely used in clinical practice to assess the cure of $\mathrm{AK}$ lesions. It is also considered appropriate when using intra-individual study design. The use of lesion clearance rate reduces the impact of confounding factors and, therefore, provides efficacy results more representative of the true clinical value of the treatment [10]. Although it has been described as a less ambitious treatment goal, the lesion clearance rate is arguably a more clinically meaningful measure of treatment effect of mild to moderate, multiple, diffuse non-hyperkeratotic AK. Therefore, it can be considered a more appropriate efficacy endpoint in trials of $\mathrm{AK}$.

Regardless of the treatment strategy selected, the goals of AK therapy remain, fundamentally, the same: to prevent progression to invasive squamous cell carcinoma, to clinically and histologically cure lesions, to minimize pain and adverse events, and to reduce recurrence. While working towards achieving these objectives, it is important to consider the reality of the everyday setting and to ensure that data available to clinicians are meaningful to their practice. Lesion response rate is a clinically meaningful measure of AK cure, both in clinical trials, as well as real-world practice, and has the potential to more accurately convey the full clinical value of a treatment and improve therapeutic decision-making in AK.

\section{ACKNOWLEDGMENTS}

Sponsorship for this study and article processing charges were funded by Galderma. All named authors meet the International Committee of Medical Journal Editors (ICMJE) criteria for authorship for this manuscript, take responsibility for the integrity of the work as a whole, and have given final approval to the version to be published. 
Disclosures. R.-M. Szeimies is Vice President of EURO-PDT. He is member of advisory boards for Almirall, Biofrontera, Galderma, ISDIN, Leo Pharma, photonamic, and Pierre-Fabre; has received speakers honoraria, and participated in clinical trials for the aforementioned companies. R. Bissonnette reports grants and personal fees from Galderma, during the conduct of the study; grants and personal fees from Leo Pharma; and personal fees from Valeant, outside the submitted work. P. Atanasov reports other fees from Galderma.

Compliance with Ethics Guidelines. This article is based on previously conducted studies and does not involve any new studies of human or animal subjects performed by any of the authors.

Open Access. This article is distributed under the terms of the Creative Commons Attribution-NonCommercial 4.0 International License (http://creativecommons.org/licenses/ by-nc/4.0/), which permits any noncommercial use, distribution, and reproduction in any medium, provided you give appropriate credit to the original author(s) and the source, provide a link to the Creative Commons license, and indicate if changes were made.

\section{REFERENCES}

1. Werner R, Sammain A, Erdmann R, Hartmann V, Stockfleth E, Nast A. The natural history of actinic keratosis: a systematic review. Br J Dermatol. 2013;169(3):502-18.

2. Salasche SJ. Epidemiology of actinic keratoses and squamous cell carcinoma. J Am Acad Dermatol. 2000;42(1):S4-7.

3. Werner R, Stockfleth E, Connolly S, Correia O, Erdmann R, Foley $\mathrm{P}$, et al. Evidence-and consensus-based (S3) Guidelines for the Treatment of Actinic Keratosis-International League of Dermatological Societies in cooperation with the European Dermatology Forum-Short version. J Eur Acad Dermatol Venereol. 2015;29(11):2069-79.

4. Philipp-Dormston WG, Sanclemente G, Torezan L, Tretti Clementoni M, Le Pillouer-Prost A, Cartier H, et al. Daylight photodynamic therapy with MAL cream for large-scale photodamaged skin based on the concept of 'actinic field damage': recommendations of an international expert group. J Eur Acad Dermatol Venereol. 2016;30(1):8-15.

5. Wolf JE, Rigel DS. Understanding efficacy end-points in studies of field-directed therapy for actinic keratosis. Int J Dermatol. 2013;52(9):1063-70.

6. Rivers JK, Wolf J. Assessing clinically meaningful end points for the management of actinic keratosis with diclofenac $3 \%$ gel. Acta Dermato-Venereologica. 2007;87(2):188-9.

7. Swanson N, Abramovits W, Berman B, Kulp J, Rigel DS, Levy S. Imiquimod $2.5 \%$ and $3.75 \%$ for the treatment of actinic keratoses: results of two placebo-controlled studies of daily application to the face and balding scalp for two 2-week cycles. J Am Acad Dermatol. 2010;62(4):582-90.

8. Korman N, Moy R, Ling M, Matheson R, Smith S, McKane S, et al. Dosing with $5 \%$ imiquimod cream 3 times per week for the treatment of actinic keratosis: results of two phase 3, randomized, double-blind, parallel-group, vehicle-controlled trials. Arch Dermatol. 2005;141(4):467-73.

9. Vegter S, Tolley K. A network meta-analysis of the relative efficacy of treatments for actinic keratosis of the face or scalp in Europe. PLoS One. 2014;9(6):e96829.

10. Szeimies RM. A network meta-analysis of the relative efficacy of treatments for actinic keratosis of the face or scalp in Europe. J Eur Acad Dermatol Venereol. 2016;30(9):1619-20.

11. Lebwohl M, Swanson N, Anderson LL, Melgaard A, $\mathrm{Xu} \mathrm{Z}$, Berman B. Ingenol mebutate gel for actinic keratosis. N Engl J Med. 2012;366(11):1010-9.

12. Pariser D, Loss R, Jarratt M, Abramovits W, Spencer J, Geronemus R, et al. Topical methyl-aminolevulinate photodynamic therapy using red light-emitting diode light for treatment of multiple actinic keratoses: a randomized, double-blind, placebo-controlled study. J Am Acad Dermatol. 2008;59(4):569-76. 